\title{
A Preliminary Study On Remote Sensing Monitoring Method For Oil And Gas Resources- A Case Study In Ordos Basin
}

\author{
Zhao Yuling ${ }^{1}$, Yang Jinzhong ${ }^{1}$, Zhang Zhi ${ }^{2}$ \\ ${ }^{1}$ China Aero Geophysical Survey and Remote Sensing Center for Land and Resources, Beijing 100083 \\ ${ }^{2}$ China University of Geosciences (Wuhan), Wuhan
}

\begin{abstract}
With the continuous improvement of the understanding of the geological law and continuous innovation of unconventional oil and gas exploration and mining technology, China has made great breakthroughs in newly-added geological reserves of unconventional oil and gas resources, such as shale gas, coalbed methane, etc. But for many reasons, attention has not been paid to oil and gas resources (petroleum, natural gas, coalbed methane, shale gas), and regional remote sensing monitoring research has not been carried out. Based on high-resolution remote sensing data of the year 2018 and human-computer interactive interpretation technique, this paper built remote sensing interpretation signs of oil and gas mines, carried out exploration of remote sensing monitoring methods for oil and gas mines, completed remote sensing monitoring over development status of oil and gas mines in Ordos Basin, and proved feasibility of remote sensing monitoring method.
\end{abstract}

\section{Intrudction}

China has abundant oil and gas resources. By the end of 2018, China had cumulative proved geological reserves of 39.877 billion tons of petroleum and 14.92 trillion $\mathrm{m} 3$ of natural gas. China's terrestrial oil and gas resources are mainly distributed in Songliao Basin, Tarim Basin, Bohai Bay Basin, Ordos Basin, Jungar Basin, Qaidam Basin, Pearl River Mouth Basin, Sichuan Basin and East China Sea Shelf Basin[1]. The petroleum resources are mainly distributed in Bohai Bay, Songliao, Tarim, Ordos, Jungar, Pearl River Mouth, Qaidam and East China Sea Shelf basins, with recoverable resources of 17.2 billion tons, accounting for $81.13 \%$ of national total petroleum resources; the natural gas resources are mainly distributed in Tarim, Sichuan, Ordos, East China Sea Shelf, Qaidam, Songliao, Yinggehai, Qiongdongnan and Bohai Bay basins, with recoverable resources of 18.4 trillion $\mathrm{m} 3$, accounting for $83.64 \%$ of national total gas resources $^{[2]}$. Moreover, China has unconventional natural gas with enormous development potential ${ }^{[3-11]}$.

At the beginning of this century, Ministry of Natural Resources (the former Ministry of Land and Resources) successively has carried out the work related to development status of national non-oil-and-gas mine resources, remote sensing survey and monitoring of geological environment of mines and others, and achieved a series of important results ${ }^{[12-18]}$. But for various reasons, current remote sensing monitoring of mines mainly focuses on solid mine resources, without relation to development survey or monitoring of oil and gas mine resources. The purpose of this paper is to explore survey and monitoring over development status of oil and gas mines based on remote sensing technology, with a view to incorporating oil and gas mines and non-oil-and-gas mines into conventional and standardized monitoring system, expanding remote sensing monitoring business of mines, widening coverage of mine monitoring and providing relevant functional departments with data support and technical support.

\section{Thoughts on remote sensing monitoring of oil and gas mines}

Oil and Gas mines are different from solid mines. Their distribution areas are relatively large. Their surface facilities (or ground objects), such as well sites (including oil production well, natural gas production well, coalbed methane production well, shale gas production well, water injection well, gas injection well, drill well, mud pile (pool), etc.), station yards (including metering station, combined station, water treatment station, gathering and transmission station, etc.), roads, oil and gas transmission pipeline, etc., are mostly unrecognizable ground objects in medium- and high-resolution remote sensing images. Monitoring development status of oil and gas mines shall be reasonably determined its work content according to monitoring purpose and main tasks.

Conventional remote sensing monitoring of oil and gas mines is based on regular monitoring. Its work tasks are to find out distribution range of oil and gas mines within a certain area, distributions and changes of well sites, station yards, etc., changes of roads in oil and gas production areas, and distribution of oil and gas 
transmission pipelines, and determine locations and areas of well sites (including production well) based on unlicensed mining, mining in place of exploration or cross-border mining by comparing related mining rights. Conventional remote sensing monitoring of oil and gas mines focuses on changes of well site and production well within a certain time interval. Since very few oil and gas production facilities are removed immediately after stopping production, mining status of well site can't be accurately distinguished from remote sensing images, for example, whether it is being mined. Therefore, this exploratory research does not pay much attention to mining status of well site and production well. Accordingly, relevant monitoring work can be carried out comparative interpretation by using remote sensing images with a spatial resolution above $2.0 \mathrm{~m}$. Emergency remote sensing monitoring of oil and gas mines is mainly carried out according to specific content. Its work tasks are to find out distribution and utilization of a certain number of well sites, station yards, etc. within a certain area, impact of activities on surrounding environment, impact of changes in surrounding environment, etc. Relevant work focuses on utilization of well sites, production wells, stations, etc., for example, whether the production wells in production can't be directly judged from remote sensing images. Currently, related work is carried out based on field validation or UAV aerial images. This paper mainly discusses relevant methods on conventional remote sensing monitoring of oil and gas mines.

combined station, water treatment station, mud pile (pool), water injection station, shale gas yard, oil gathering station, station yard, perforation room for special energy-gathered perforation equipment, temporary site, roads in oil and gas areas (width: $4 \mathrm{~m}$ and above), gas transmission pipeline (width: $4 \mathrm{~m}$ and above), oil transmission pipeline (width: $4 \mathrm{~m}$ and above), etc.; and polyline factors, such as roads in oil and gas areas (width: $4 \mathrm{~m}$ and below), gas transmission pipeline (width: $4 \mathrm{~m}$ and below), oil transmission pipeline (width: $4 \mathrm{~m}$ and below), etc.

To this end, we have built special remote sensing interpretation signs based on remote sensing images and field validation data.

\section{Technical process and work methods for remote sensing monitoring of oil and gas mines}

According to work experience in remote sensing monitoring of solid mines, the process of remote sensing monitoring of oil and gas mines at least includes data preparation, information extraction, field validation, integrated research, result compilation, etc.,( Figure 1).

\subsection{Data preparation}

\subsubsection{Collection of basic data}

\section{Determination of remote sensing monitoring factors of oil and gas mines and remote sensing interpretation signs}

Remote sensing monitoring of oil and gas mines involves the following main mineral varieties: petroleum, natural gas, coal bed methane and shale gas. Main steps for exploitation and development of oil and gas fields are as follows: geological exploration - geophysical prospecting - well drilling - well logging - well measuring - well cementing - well completion - perforation - oil production - well repair - mining increase - transmission - processing. In view of interpretability of remote sensing image, this remote sensing monitoring objects of oil and gas mines are drill well, oil production, mining increase and transmission.

According to field exploration in Ordos Basin Demonstration Area, various facilities in oilfield exploitation process, and land occupation of various parts in remote sensing images, and the main content in Land Control Indicators for Oil and Gas Construction Projects issued by Ministry of Natural Resources (the former Ministry of Land and Resources) in 2017, factors and contents for remote sensing monitoring of oil and gas mines are preliminarily determined as follows: point factors, such as drill well, oil production well, water injection well, gas injection well, natural gas production well, coal bed methane production well, shale gas production well, etc.; polygon factors, such as well site, metering station, oil and gas station, oil gathering room,

According to work purpose and work area range, we collect regional natural geographic background data, geological environment data, oil and gas resources distribution data, topographic map, DEM data, etc.; acquire remote sensing image data in the work area, carry out quality inspection of remote sensing data, eliminate unqualified data and supplement remote sensing data above $2.0 \mathrm{~m}$; collect completed remote sensing results in the work area, and understand construction of remote sensing interpretation signs. Moreover, we give priority to collection of latest, high-accuracy data in the principle of data collection from new to old time and from high to low accuracy, and strengthen comprehensive analysis of data and determine difficulties and focuses of work in the principle of combining remote sensing data with other multi-source data.

\subsubsection{Production of monitoring base map}

Monitoring base map shall be produced by using remote sensing data with a spatial resolution above $2.0 \mathrm{~m}$. Accuracy of monitoring base map shall meet the requirements of national standards or industrial standards.

\subsection{Information extraction and field validation}

The technology roadmap of combining computerautomated information extraction with human- computer 
interactive interpretation, and combining indoor integrated research with field survey can enhance accuracy of information extraction.

\subsubsection{Information extraction}

Information extraction shall be carried out according to the technology roadmap of combining computerautomated information extraction with human- computer interactive interpretation. Linear ground objects such as roads in oil and gas areas, oil and gas transmission pipeline, etc. can be carried out computer-automated information extraction in combination with human-computer interactive interpretation by such ways as image texture extraction, density slicing, color transformation, etc. Point-like ground objects such as production well and plane-like ground objects such as well site/station yards shall be built remote sensing interpretation and recognition signs for ground objects of oil and gas mines according to purpose of survey and monitoring, and extracted relevant information from oil production well, natural gas production well, coalbed methane production well, shale gas production well, drill well, water injection well, gas injection well, well site, metering station, combined station, water treatment station, mud pile/pool, temporary site, oil gathering room and more through visual interpretation based on multi-period remote sensing images.

\subsubsection{Field validation}

According to ground object resolutions in various remote sensing data, difficulty level of ground object recognition of oil and gas mines, a certain proportion of map spots

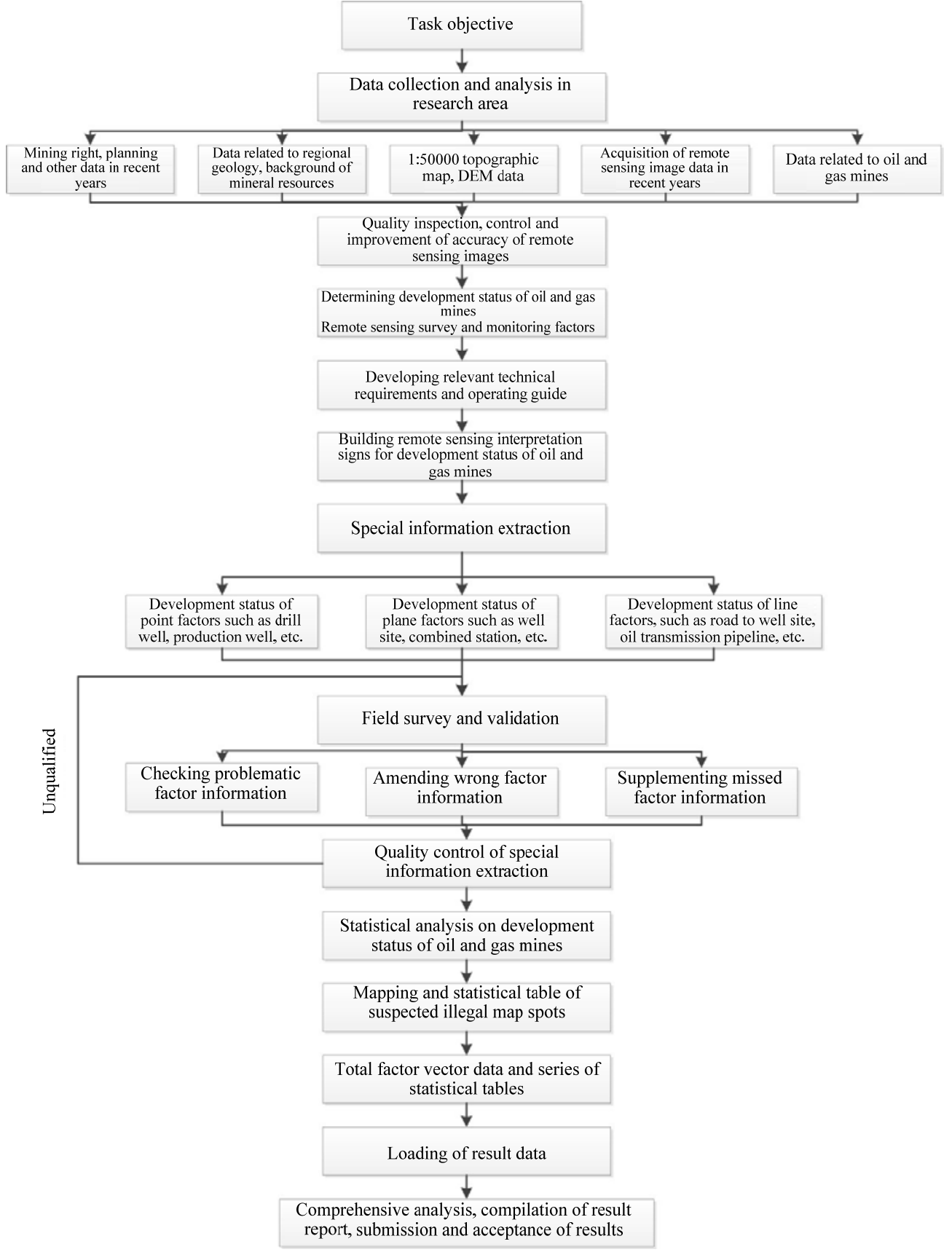

Fig.1. Technology Roadmap for Remote Sensing Monitoring of Oil and Gas Mines 
shall be selected to carry out field validation. Firstly, amend and perfect remote sensing interpretation signs of ground objects of established oil and gas mines, and find out related information inside the well site, such as quantity of production wells, mining status, etc. so as to lay a solid foundation for further interpretation of relevant interpretation information; secondly, carry out field validation over partially extracted information, eliminate wrongly extracted map spots, perfect uncompleted map spots of extracted information, supplement missed map spots, and sum up experience and lessons of information extraction; thirdly, we conduct analysis and summary of recognition capability of ground objects with various spatial resolutions and various data sources, conduct secondary extraction and interpretation of regional information, and enhance accuracy of information extraction.

\subsection{Integrated research and result compilation}

According to interpretable degree of remote sensing image, determine factor type and expression form of remote sensing monitoring of oil and gas mines; develop contents and forms of relevant technical requirements, operating guide, result data expression; compile result map as required. Through analysis and research of extracted information on oil and gas fields, complete development status survey of oil and gas resources, survey and research of triggered geological environment issues, and compile a special report. Submit results and carry out application services as scheduled.

\section{Monitoring experiment}

\subsection{Geographical and geological conditions in experiment area}

Ordos Basin in the experiment area is located in the central and western regions of China, being China's second largest sedimentary basin (ranking second among the four largest basins in China). Ordos Basin stretches from Yinshan Mountain and Daqingshan Mountain in the north, to Longshan Mountain, Huanglong Mountain and Qiaoshan Mountain in the south, to Helan Mountain and Liupan Mountain in the west, and to Luliang Mountain and Taihang Mountain in the east, with a total area of nearly $370,000 \mathrm{~km} 2$; its terrain is high in the east and low in the west, and slopes gently, with a slope of less than $1^{\circ}$ per kilometer; its administrative district stretches across Shaanxi, Gansu, Ningxia, Mongolia and Shanxi provinces. Ordos Basin is superimposed on the early and late Paleozoic large basins in North China, and characterized by stable subsidence, depression migration, obviously twisted polycyclic subsidence. Ordos Basin is a multiple superimposed inland basin developed from the middle and late Triassic to the early Cretaceous, and then reconstructed during multiple periods.
In Ordos Basin, proved reserves of natural gas, coalbed methane and coal rank first, and proved reserves of petroleum rank fourth among national basins; the characteristics of oil and gas gathering in Ordos Basin are "semi-basin oil, full-basin gas, oil in the south and gas in the north, oil on the top and gas on the bottom". Transversely, Ordos Basin features its large area, wide distribution, composite continuous area and multi-layered system. Longitudinally, Ordos Basin has "four-storeyed" oil-bearing layer system, known as "Treasure Basin"[19-23].

\subsection{Working process}

This experiment acquired remote sensing data of research area in 2018, involving the following main satellite types: GF1, ZY3, 02C, SPOT6, VW2, GF2, BJ2, SJ9, etc., with a spatial resolution above $2 \mathrm{~m}$. For vegetated, cloudy or individual low-resolution images, Google Earth images can be used as a supplement. Field survey and validation are based on indoor interpretation analysis. Accuracy rate of field map spots validation is up to $90 \%$.

\subsection{Experiment result}

Mineral varieties of oil and gas mines reserved in Ordos Basin are as follows: petroleum, natural gas, coalbed methane and shale gas. There are multiple oil and gas fields in Ordos Basin: PetroChina Changqing Oilfield Company, Shaanxi Yanchang Petroleum (Group) Co., Ltd., Sinopec North China Oil and Gas Branch, PetroChina Company Limited, PetroChina North China Oilfield Company, PetroChina Coalbed Methane Company Limited.

Remote sensing monitoring result indicates that: In Ordos Basin, 66,255 well sites, including 123,605 oil (gas) production wells and 1,092 drill wells, have a total area of $293,090,378 \mathrm{~m} 2$; other facilities have a total area of $291,789,200 \mathrm{~m} 2$. Moreover, there are 14,207 suspected illegal well sites with a total area of $36,151,122 \mathrm{~m} 2$; and 40,556 suspected illegal production wells (An example of result map can be seen in Figure 2.) Among exploitation and mining areas of PetroChina, Sinopec and Yanchang Oilfield, Yanchang Oilfield has the largest number of suspected illegal production wells, up to $61.72 \%$, PetroChina $36.67 \%$, and Sinopec $1.62 \%$. Detailed statistics are shown in Table 1. There are relatively serious suspected illegal phenomena in the research area, appearing as mining in place of exploration and cross-border mining. The mining in place of exploration accounts for the largest proportion of suspected illegal map spots: Quantity of well sites based on the mining in place of exploration accounts for $96.31 \%$ that of suspected illegal well sites. Quantity of production wells based on the mining in place of exploration accounts for $98.36 \%$ that of suspected illegal production wells. For the cross-border mining, quantity of well sites based on cross-border mining accounts for $2.81 \%$ that of suspected illegal well sites, and quantity of 
oil and gas production wells based on the cross-border mining accounts for $1.23 \%$ that of suspected illegal oil and gas production wells.

Experiments found that: (1) Type, location, number and area of well sites within oilfield blocks can be found out by using remote sensing data above $1 \mathrm{~m}$, and location, number, etc. of drill well, production well, etc. can be found out by using high-resolution remote sensing image above $0.5 \mathrm{~m}$. (2) Roads to well site and locations of various well sites can be interpreted to a high degree. Water injection station (characterized by water tank), combined station (characterized by oil tank and water tank), and metering station (characterized by its adjacency to water injection station) can be interpreted to a medium degree. Oil transmission pipeline can be interpreted to a low degree. The map spots of combined station, station yard and petrochemical plant are easily confused. Upon interpreting and judging, attention shall be paid to upright chimneys or relatively dense vertical tubular ground objects. Characteristics of map spots of cemetery in the northwestern part of Ordos Basin in the remote sensing image with a resolution below $2 \mathrm{~m}$ are extremely similar to those of well sites with mining trees, which are easy to cause misjudgment. In the remote sensing image, water injection well and gas injection well be confirmed. Only through field validation can quantity and attribute of water injection wells and gas injection wells be found out accurately. (3) Vegetation and farm crops in the northwest part of Ordos Basin are flourishing in summer and autumn, which are easy to cause occlusions. It is recommended to use remote sensing images in winter, because small solar elevation angle and shaded open line of small pumping unit (from November to March of next year) are easy to recognize and distinguish oil production well, drill well and other equipment. Due to the complex landscape in the centralregion, the contrast between the well sites and the background in the image is very big. It is recommended to use summer remote sensing data.

Table 1. Statistical Table for Remote Sensing Interpretation Map spots of Oil and Gas Mines of Relevant Oil Enterprises in Ordos

\begin{tabular}{|c|c|c|c|c|c|c|c|c|c|}
\hline \multirow[b]{2}{*}{ Names of oil enterprises } & \multicolumn{4}{|c|}{ Total of suspected illegal map spots } & \multicolumn{5}{|c|}{ Total of legal map spots } \\
\hline & $\begin{array}{c}\text { Quantity } \\
\text { of well } \\
\text { sites }\end{array}$ & $\begin{array}{c}\text { Quantity of } \\
\text { production } \\
\text { wells }\end{array}$ & $\begin{array}{c}\text { Quantity } \\
\text { of drill } \\
\text { wells }\end{array}$ & $\begin{array}{l}\text { Area of } \\
\text { well site } \\
\left(\mathrm{m}^{2}\right)\end{array}$ & $\begin{array}{l}\text { Quantity } \\
\text { of well } \\
\text { sites }\end{array}$ & $\begin{array}{c}\text { Quantity of } \\
\text { production } \\
\text { wells }\end{array}$ & $\begin{array}{l}\text { Quantity } \\
\text { of drill } \\
\text { wells }\end{array}$ & $\begin{array}{c}\text { Area of well } \\
\text { site }\left(\mathrm{m}^{2}\right)\end{array}$ & $\begin{array}{c}\text { Area of } \\
\text { other } \\
\text { relevant } \\
\text { facilities } \\
\left(\mathrm{m}^{2}\right)\end{array}$ \\
\hline PetroChina & 5419 & 14871 & 0 & 18429054 & 43681 & 75931 & 950 & 216918691 & 244225550 \\
\hline $\begin{array}{c}\text { Shaanxi Yanchang } \\
\text { Petroleum (Group) Co., } \\
\text { Ltd. }\end{array}$ & 8610 & 25030 & & 16452216 & 6225 & 6238 & 86 & 26401749 & 14700050 \\
\hline Sinopec & 176 & 655 & & 1264516 & 2132 & 880 & 56 & 13534904 & 32796129 \\
\hline $\begin{array}{l}\text { China United Coalbed } \\
\text { Methane Corp. Ltd. }\end{array}$ & & & & & 9 & & 1 & 92984 & 70013 \\
\hline $\begin{array}{c}\text { Area without mining } \\
\text { right }\end{array}$ & 2 & & & 5336 & 10 & & & 83912 & 67471 \\
\hline Total & 14207 & 40556 & 0 & 36151122 & 52048 & 83049 & 1092 & 256939256 & 291789200 \\
\hline
\end{tabular}




\section{Distribution Image for Suspected Illegal Map Spots of Oil and Gas Mines}

County-level Administrative District: Shaanxi Province, Yan'an City $\$ \$ \$$ County

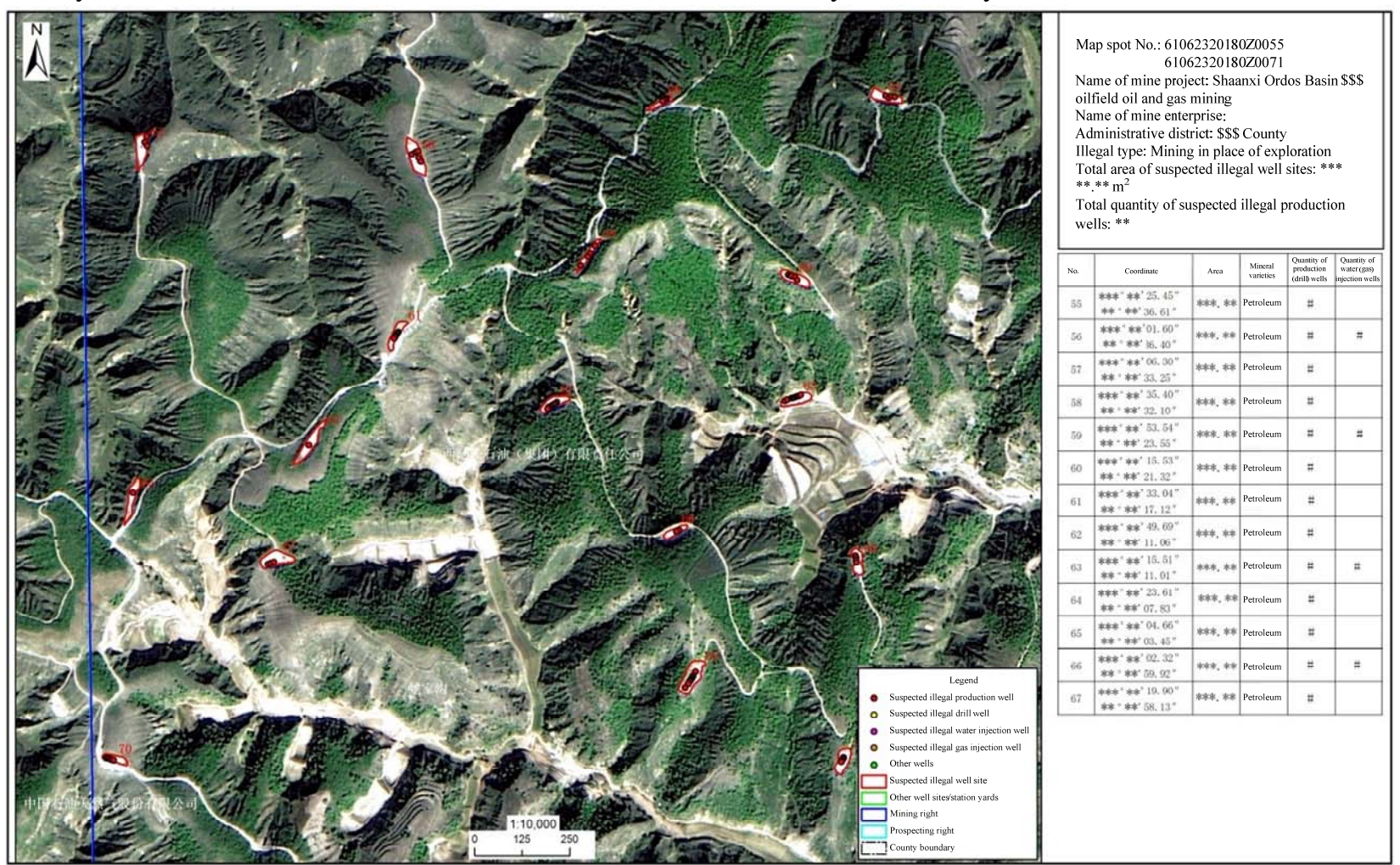

Source: Remote Sensing Data for Land Use Change Survey 2018

Fig. 2. An Example of the Distribution Image for Suspected Illegal Map Spots of Oil and Gas Mines

\section{Conclusions and recommendations}

(1) It is highly feasible to monitor development status of oil and gas mines by using remote sensing images, which can be carried out on a national scale.

(2) Experiments have proved that remote sensing recognition method for ground objects of oil and gas mines, relevant technical requirements and operating guide are highly feasible, which can provide technical support for remote sensing monitoring of oil and gas mines and related work.

(3) It is recommended to survey range and influence degree of oilfield-related geological environment issues, such as ground subsidence, salinized soil, water pollution, etc. over key steps and key areas in the development procedure of oil and gas fields by combining with multi-source remote sensing data, such as active/passive, middle- and high- resolution, high-spectrum data. In accordance with regulatory requirements of national space standards, remote sensing surveys of the lands for various oilfield facilities are carried out to find out types and areas of the lands for various oilfield facilities, which can provide data support for supervision of oilfield lands.

Acknowledgements: Thank for support from China Aero Geophysical Survey and Remote Sensing Center for Land and Resources. Thank Han Ziye, Xiong Shengqing, Ge Xiaoli, Xing Yu, Liu Qiong, Wang Haiqing, Wang Yanzuo, Anna, Yao
Weiling, Wang Hao, Wang Jie, Li Li, Yin Yaqiu, Sun Yaqin, Zhou Yingjie and Shuai Shuang. In addition, we express our sincere thanks to two master students of China University of Geosciences (Beijing): Chen Xiaohan who has made a contribution in the early stage of this work, and He Jinbao who has made a contribution in the field survey and validation. Special thanks to comrades who have worked hard in the interpretation of oil and gas mines: Xue Qing, Zhao Mingpeng, Zeng Guang, Yu Lei, Yang Wenfang, Feng Chenwei, Yang Xianhua, Xiao Lixiao, Peng Bei, Zheng Jiwei, Lu Dingbiao, Yang Yiwei, Yang Zikun, Li Sifa, Lu Fei, Li Yuan, Cui Xian, Ma Taofeng, Zang Yuchen, Li Si, Tang Panke, Niu Haiwei, Huang Xuhong, Zheng Jian and Dong Hang.

Fund project: The work is jointly funded by China Geological Survey Project "Remote Sensing Geological Survey and Monitoring of National Mine Development Status (No.: DD20190511), and "Remote Sensing Geological Survey and Monitoring of National Mine Environment Restoration and Governance Status" (No.: DD20190705).

\section{References}

1 Latest Data of Chinese Oil and Gas Resources [EB/OL].

http://www.sohu.com/a/322821094_738924,2019-0 6-24 17:59

2 An Analysis on Overview of Petroleum Resources Development, Production Scale of Crude Oil, Supply and Demand Status of Petroleum, and the 
Latest Development Trend of Petroleum Industry in $\begin{array}{lll}\text { China } 2017 & \text { [EB/OL]. }\end{array}$ http://www.chyxx.com/industry/201707/544139.htm 1, 2017-07-25 13:16:43

3 X. Sun, B. Zhang, X. Wei, et al. Overview of Evaluation and Impacts over Exploration and Development of Unconventional Natural Gas [J].China Mining Magazine. 25(3):1-10 (2016)

4 Y.Y. Li, X.K. Fu, Q.S. Li, et al. Current Situation of Study on Chinese Coalbed Methane Exploitation Technology [J]. Petrochemical Industry Application. (4): 1-4, 10 ( 2019)

5 J.W. Teng, Y.S. Liu. An Analysis on Distribution, Storage Potential and Prospect of Chinese Oil and Gas Shales [J]. Progress in Geophysics. (3): 1083-1108(2013)

6 G.F. Yang. Two Highlights of Global Oil and Gas Exploration and Development [J]. Sinopec, (1): 71-75(2018)

7 D.Z. Dong, C.N. Zou, H. Yang, et.al. Progress and Prospects of Shale Gas Exploration and Development in China [J]. Acta Petrolei Sinica, 33 (A01): 107-114(2012)

8 F.Y. Sang. A Study on Current Situation of Global Development of Low-rank Coalbed Methane and its Development Potential in China [J]. China Coalbed Methane. 12 (3): 7-9 (2015)

9 W. Guo, J.P. Pan. Mid-term Evaluation and Prospect of Implementation of the 13th Five-Year Plan for Exploration and Mining of National Oil and Gas Resources [J]. Natural Gas Industry, (4): 111-117(2019)

10 Y.W. Chang, Z.G. Wang, B.L. Liu, et al. Situation Review and Trend Outlook of Global Oil and Gas Development 2017 [J]. Oil Forum, (5): 64-74(2018)

11 X.M. Liu. Current Situation, Challenges and Technology Development Direction of Chinese Oil and Gas Field Development [J]. Technology and Industry Across the Straits. (3): 146-147(2017)

12 J. Z. Yang, X. W. Qin, H. F. Nie, et al. Guidelines for Remote Sensing Monitoring of Mines [M]. Beijing: China Land Press, (2009)

13 J. Z. Yang, X. W. Qin, Z. Zhang, et al. Theory and Practice on Remote Sensing Monitoring of Mines [M]. Beijing: Surveying and Mapping Press, (2011)

14 X. W. Qin,J. Z. Yang, G. F. Kang, et al. A Study on Remote Sensing Monitoring Techniques of Mines [M]. Beijing: Surveying and Mapping Press,( 2011).

15 J. Z. Yang, X. W. Qin, H. F. Nie, et al. Remote Sensing Monitoring of Mines in China [M]. Beijing: Surveying and Mapping Press, (2014)

16 J. Z. Yang, H. F. Nie, H. Q. Wang, et al. Remote Sensing Monitoring of Geological Environment of Mines in China (2015) [M]. Beijing: Geological Publishing House, (2017)

17 J. Z. Yang, H. Wang, S. F. Dong, et al. Remote Sensing Monitoring of Geological Environment of
Mines in China (2016) [M]. Beijing: Geological Publishing House, (2018)

18 J. Z. Yang, X. W. Qin, H. F. Nie, et al. An Integrated Study on Remote Sensing Monitoring of Mines in National Key Mining Areas[J]. China Geological Survey, 2(04): 24- 30(2015)

19 H.T. Wu, M.X. Sun. Brief description of tectonic evolution of Ordos Basin [J]. Science \& Technology Information. (7)78-79,81 (2019)

20 H.J. Qu, R.H. Pu, S. Chen,et al. Phase-Potential Coupling Control over Accumulation of Mesozoic Oil in the Ordos Basin [J]. Oil \& Gas Geology. 40 (4): 752-762,874(2019)

21 Q. Fu, J. Li, X.Q. Deng, et al. Impact of Sedimentary Events on Deep Water Sedimentation Process: Taking Chang 6 Oil Reservoir Group in Huaqing Area of Ordos Basin as an Example [J]. Lithologic Reservoirs. 31 (1): 20-29(2019)

22 X. Feng, K.X. Qu, Q. Xiong, et al. An Analysis on Reservoir Forming Characteristics of Tight Large Gas Fields in China - Taking Ordos Basin and Sichuan Basin as Examples [J]. Chemical Enterprise Management. (4) 215-220(2019)

23 J.Y. Liu, Y. Zhang, Z.Y. Gao, et al. Oil and Gas Field Development and Environmental Protection in Western China [J]. Petrochemical Industry Technology. (2): 106-106,143(2019) 